\title{
NAVORSINGSMETODOLOGIE HOE OM BEHOEFTES IN DIE GEMEENSKAP TE BERAAM
}

\section{DR MARIE POGGENPOEL}

\section{Lektrise, Psigiatriese Verpleegkunde, Randse Afrikaanse Universiteit}

\section{SUMMARY}

An assessment of community needs is part of the scientific process used by the multi-professional health team to assess, plan, implement and evaluate a community health service.

An accurate assessment of both perceived needs and those identified by health professionals is necessary for an effective service. Such an assessment requires the use of research methodology, including scientific research methods, techniques and instruments. There are also a number of essential questions to which answers must be found by the research to ensure a comprehensive assessment.

\section{EVERY MAN HAS A RIGHT TO HIS OPINION, BUT NO MAN HAS A RIGHT TO BE WRONG IN HIS FACTS - Bernard Baruch (Young, 1956, p. 115)}

\section{INLEIDING}

Die beraming van behoeftes in die gemeenskap maak deel uit van 'n wetenskaplike proses waarin die multiprofessionele span en dus ook die verpleegkundige 'n effektiewe gemeenskapsdiens lewer deur die beraming, beplanning, implementering en evaluering van omvattende gesondheidsorg. Hierdie beraming van behoeftes in die gemeenskap kan dus ook as toegepaste of as vlak een navorsing beskou word. Die vraag word gestel: wat, waar, wanneer en wie? Die doel van hierdie navorsing is om te verklaar en inligting te bied. Die ontwerp van dié navorsing is ondersoekend en beskrywend van aard. Die metode kan ongestruktureerde waarneming, oop-eindeonderhoude, deelnemende waarneming, vraelyste, geskrewe en ongeskrewe beskikbare data, statistieke (sensusopnames, gemeenskapsdiensstatistieke) en skedules insluit. 'n Analise van die verkreë inhoud vind plaas sowel as die daarstelling van stastistieke, grafieke en tabelle. Die resultaat bied ' $n$ be- skrywing, konsepte, kategorieë van veranderlikes en prosesse aan. Op grond hiervan kan die ondersoeker tot 'n slotsom raak oor die gesondheid en behoeftes van die gemeenskap waarvolgens tussentredes beplan kan word. (Brink \& Wood, 1978, p.i.; Haber, Leach, Schudy \& Sidleau, 1978, p. 17; Werley, Zuzich, Zajkowski \& Zagornik, 1976 p. 190)

Omdat die beraming van behoeftes in die gemeenskap deel uitmaak van 'n wetenskaplike proses sal daar vervolgens gekyk word na die gebruik van navorsingsmetodologie in die beraming van behoeftes in die gemeenskap; waarom gebruik gemaak word van navorsing in hierdie beramingstap; die behoefte-aanvraag verhouding, en beraming van die gemeenskap en laastens tot 'n slotsom geraak word.

\section{DIE GEBRUIK VAN NAVOR- SINGSMETODOLOGIE IN DIE BERAMING VAN BEHOEFTES IN DIE GEMEENSKAP}

In die beraming van behoeftes in die gemeenskap word van 'n wetenskaplike benadering gebruik gemaak. Navorsingsmetodologie dui op die geldigheid van die gebruik van navorsingsprosedures, -tegnieke en ontwerp van navorsing (Cilliers, 1965, p. 166).

Die doelstelling van metodologie is die verbetering van die prosedures en kriteria wat gebruik word in die uitvoering van wetenskaplike navorsing (Ackoff, 1962, p. 546). Wetenskaplike metodes, tegnieke en instrumente maak alles deel uit van navorsingsmetodologie.

\section{Wetenskaplike metode}

'n Wetenskaplike metode verwys na die wyse waarop tegnieke gekies word in die wetenskap, dit is die evaluering van alternatiewe wyses van wetenskaplike optrede (Ackoff, 1962, p. 586). Die algemeenste metode wat gebruik kan word om behoeftes in die gemeenskap te beraam is die gebruik van die opname (survey). Die opnamemetode word dan ook gedefinieer as die wetenskaplike studie van die 
gemeenskap se toestand en behoeftes met die doel om 'n konstruktiewe program vir sosiale vooruitgang daar te stel. Dit is 'n metode van sosiale introspeksie wat gekontroleer word deur statistiese metings en die vergelyking van gestelde norme (Young, 1956, p. 18; Krampitz \& Pavlovich, 1981; p. 59; Abramson, 1974, p.1-177; Abdellah, 1979, p. 335).

\section{Verskillende opname-metodes}

Verskillende opname-metodes word slegs kortliks aangedui met verwysings na waar verdere inligting bekom kan word.

Direkte waarneming behels dat die ondersoeker self waarnemings maak van die gemeenskap. Direkte waarneming kan op gekontroleerde of ongekontroleerde wyse gedoen word. In eersgenoemde geval sal die ondersoeker van hulpmiddele gebruik maak om sy waarnemings te standaardiseer sodat dit verifieerbaar is. (Cilliers, 1965, p. 44; Fox, 1976 p. 210-213; Diers, 1979 p. 245-253; Krampitz \& Pavlovich, 1981, p. 64-65.

Persoonlike mededelinge: Hier het ons met indirekte waarneming te doen wat op die persoonlike mededelinge van ander gebaseer is.

- Vraelyste (Young, 1956, p. 176203; Cilliers, 1965, p. 92-94; Krampitz \& Pavlovich, 1981, p. 60-62; Diers, 1979, p. 253-263; Fox, 1976, p. 216-219; Williamson, 1981 p. 217-228; Bennet \& Ritchie, 1975, p. 1-97).

- Onderhoudvoering (Young,
1956, p. 205-226; Cilliers, 1965, p. 88-92; Krampitz \& Pavlovich, 1981, p. 62-64; Diers, 1979, p. 253-263; Fox, 1976, p. 216-219).

- Gevalledata soos gevallestudies waar persoonlike dokumente en agtergrondgeskiedenis gebruik word. (Young, 1956, p. 229-233; Cilliers, 1965, p. 66-68)

Statistieke dui die mate, frekwensie en mate van assosiasie aan, byvoorbeeld sensusstatistieke; Departement Gesondheid en Welsyn se statistieke oor die insidensie en voorkoms van ongesteldheid, personeelvoorsiening in dienste; plaaslike gemeenskapsgesondheidsentrum-statistieke.

\section{Wetenskaplike tegniek}

Dit verwys na 'n wyse om wetenskaplike doelstellings te bereik, 'n wetenskaplike optreewyse. Tegnieke is daarom wyses om wetenskaplike instrumente te gebruik. Steekproefneming en rangordeskale is byvoorbeeld tegnieke. Getratifiseerde toevallige steekproefneming is dus 'n tegniek en dit gebruik die toevallige getalsbepaling as instrument (Ackoff, 1962, p. 506; Fox, 1976, p. 224-239).

Streekproefneming behels die seleksie, toevallig of nie-toevallig van 'n aantal persone uit 'n gemeenskap wat verteenwoordigend is van die gemeenskap waartoe hulle behoort. Die persone wat aan die ondersoek deelneem, moet dus 'n goeie weergawe bied van die gemeenskap in al sy aspekte, sodat die eienskappe van die persone ook vir die gemeenskap sal geld. Steekproewe word gebruik omdat dit nie altyd moontlik is om waarnemings te maak van al die persone in 'n gemeenskap wat tot ' $n$ bepaalde klas van verskynsels behoort nie. Hoe groter die universum (aantal persone in die gemeenskap) hoe kleiner is die proporsie wat die steekproef van die universum hoef uit te maak (Cilliers, 1965 p. 106-112; Abdellah, 1979 , p. 318 335; Williamson, 1981, p. 169-188).

\section{Wetenskaplike instrument}

Dit verwys na 'n fisiese of konseptuele instrument wat in die wetenskaplike ondersoek gebruik word. Matematiese simbole en tabelle van toevallige getalle is daarom instrumente. (Ackoff, 1962, p. 546).

In hierdie afdeling is kortliks verwys na die gebruik van navorsingsmetodologie in die beraming van gesondheidsbehoeftes in die gemeenskap.

\section{WAAROM NAVORSING? EFFEKTIWITEIT IN DIE VERVULLING VAN BEHOEFTES IN DIE GEMEENSKAP}

(Silverman, 1981, p. 22 \& 23; Haber et al., 1978, p. 15 \& 16; Uys, 1981, p. 91-99; Freedman, Kaplan \& Sadock, 1977, p. 1172-1180)

Die gemeenskapsgesondheidsdienssentrum se oorkoepelende doelstellings is om die gesondheids-

\section{Tabel 1: EFFEKTIWITEITSGEBIEDE VIR 'N GEMEENSKAPSGESONDHEIDSENTRUM}

(Silverman, 1981, p. 23)

\begin{tabular}{|c|c|c|c|c|c|c|c|}
\hline \multirow[b]{2}{*}{$\begin{array}{l}\text { Administratiewe } \\
\text { gebiede }\end{array}$} & \multicolumn{5}{|c|}{ Program of diens gebiede } & \multicolumn{2}{|c|}{ Prosesgebiede } \\
\hline & $\begin{array}{l}\text { Gesond- } \\
\text { heidsbe- } \\
\text { vordering }\end{array}$ & $\begin{array}{c}\text { Spesifieke } \\
\text { beskerming }\end{array}$ & $\begin{array}{l}\text { Vroeë op- } \\
\text { sporing en } \\
\text { behandeling }\end{array}$ & $\begin{array}{c}\text { Beperking } \\
\text { van } \\
\text { gebrek }\end{array}$ & Rehabilitasie & $\begin{array}{c}\text { Responsi- } \\
\text { witeit op } \\
\text { gemeenskaps- } \\
\text { behoeftes }\end{array}$ & $\begin{array}{l}\text { Plaaslike } \\
\text { Finansiering }\end{array}$ \\
\hline Beplanning & & & & & & & \\
\hline Organisering & & & & & & & \\
\hline $\begin{array}{l}\text { Personeel- } \\
\text { voorsiening }\end{array}$ & & & & & & & \\
\hline Direksie, rig & & & & & & & \\
\hline Beheer & & & & & & & \\
\hline
\end{tabular}


behoeftes van die kliënte in sy diensarea te bevredig. Vir die doeleinde van hierdie artikel is dit nie noodsaaklik om ooreen te kom oor 'n enkele definisie van 'n gesondheidsbehoefte nie. Hierdie behoeftes varieer as 'n funksie van die waarnemings en waardes van elke gemeenskap. Daar sal vervolgens 'n algemene benadering ten opsigte van gemeenskapsbehoeftes aangedui word wat gebaseer is op 'n groep veronderstellings. Die funksies, prosesdoelstellings en administratiewe proses kan as basis dien in die bepaling en vervulling van behoeftes in die gemeenskap.

Die verskeie funksies van 'n gemeenskapsgesondheidsentrum kan geklassifiseer word in die volgende effektiwiteitsgebiede (Sien ook tabel 1)

Gesondheidsbevordering. Die doelstellings hier is om gesondheidsproduserende omgewingsfaktore te versterk en die ontwikkeling van gesondheidsinhiberingsfaktore te voorkom.

Spesifieke beskerming. Hierdie doelstellings is daarop gemik om 'n verdediging teen versteurings daar te stel deur die uitskakeling van essensiële veroorsakende faktore.

Bespeuring en behandeling van versteurings. Hierdie doelstellings is betrokke by die daarstelling van remediële maatreëls.

\section{Diagram 1: BEHOEFTE-AANVRAAG-VERHOUDINGS (aangepas van Grundy \& Reinke 1973, p. 30)}

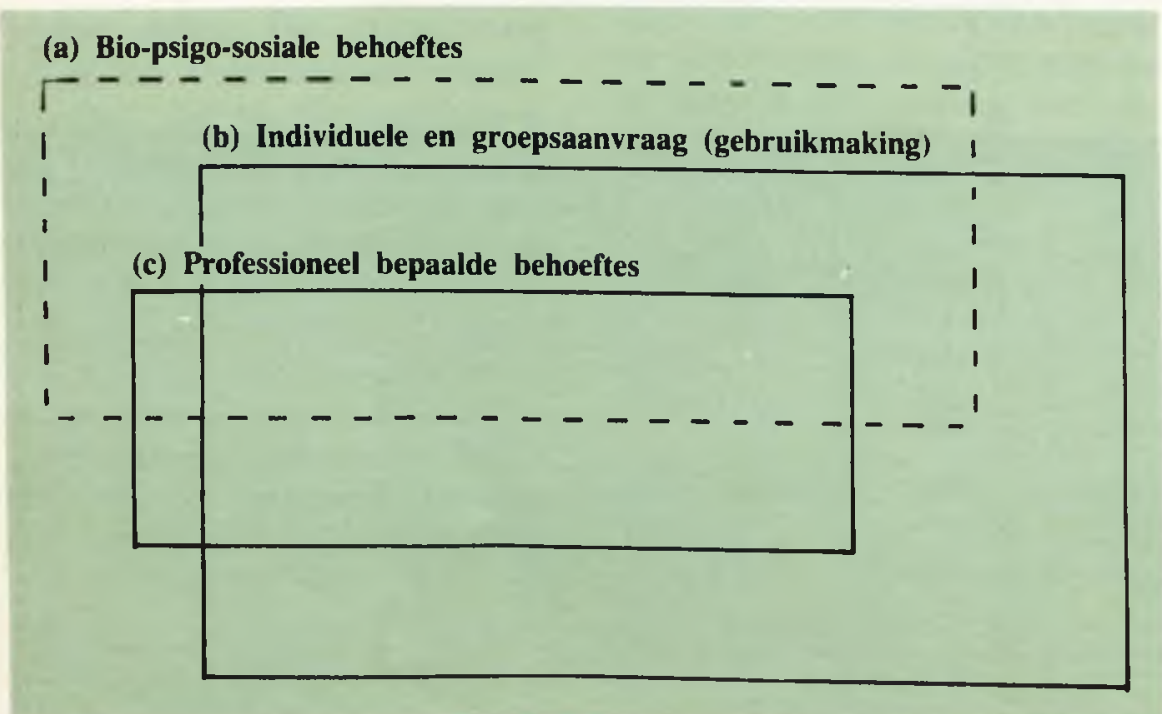
Hierdie doelstellings handel oor die blokkering van agteruitgang en die bewaring van normale funksionering.

Rehabilitasie. Dié doelstellings is betrokke by die herstelling van die individu tot die hoogste vlak van onafhanklike aktiwiteit waartoe hy/sy in staat is.

'n Ander effektiwiteitsgebied is prosesdoelstelling. Hierdie doelstelling is verwant aan die vereiste dat die gemeenskapsgesondheidsentra respons toon op die gemeenskapsbehoefte; die effektiwiteitsgebied wat hierdie doelstelling insluit is responsiwiteit op gemeenskapsbehoeftes. Funksies hier handel oor effektiewe dienste wat toeganklik, toereikend in volume, gepas is vir die dienspopulasie se prioriteitsbehoeftes, en aanvaarbaar vir en bekend aan die populasie is. ' $n$ Tweede soort proses-effektiwiteitsgebied is plaaslike finansiering.

Saam met die effektiwiteitsgebiede wat die uiteinde van die diensprogramme en proses betrek, is daar algemene take wat verwant is aan elke effektiwiteitsgebied en die doelstellings wat in elkeen voorkom. Hier word na die administratiewe proses verwys wat van toepassing is op elke program. Die hoofstappe in hierdie proses is beplanning, organisering, personeel-
Beperking van gebrek of aantasting.

\section{DIE BEHOEFTE-AANVRAAG- VERHOUDING}

(Grundy \& Reinke, 1973, p. 29-31)

'n Oorkoepelende doelstelling in die meeste gesondheidsbeplanning en in die organisasie van gesondheidsdienste is om die behoeftes van 'n bevolking (populasie) te bevredig, of om die voorsiening en aanvraag te laat ooreenkom.

Aanvraag wat gewoonlik gemeet word deur gebruikmaking van diens, gee 'n redelike goeie aanduiding van die dienste wat nodig is. Dit is egter belangrik om in gedagte te hou dat aanvraag die behoefte onderskat. In alle gemeenskappe is daar mense wat gesondheidsorg nodig het wat dit nie aanvra nie. Hulle kan ongesteld (siek) wees sonder om dit te besef; hulle kan 'n gebrek of versteuring as normaal aanvaar; en hulle kan uit onkunde, onbelangstelling, vooroordeel, aanvaarding, vrees, luiheid of weerstand nie op ' $n$ beskikbare diens reageer nie. Verbruikers se respons word ook beïnvloed deur faktore soos toeganklikheid van die diens in terme van afstand, tyd en koste, kompeterende eise in ander sfere, en deur die kwaliteit van die dienste en hulle noodsaaklikheid uit die verbruikers se oogpunt gesien.

Die nie-ooreenkoms tussen biopsigo-sosiale behoeftes, aanvraag en professioneel bepaalde doelstellings word diagramaties aangedui in diagram 1. 'n Stippellyn word vir bio-psigo-sosiale behoeftes gebruik om aan te dui dat hulle nie vasgestelde grense het nie. Dit word voorgestel dat die verskille wat aangedui word na verwant is aan vlakke van ontwikkeling. Verskille is geneig om kleiner te wees wan- 
Tabel 3: 'N ANALISE VAN TYD TOEGEWYS AAN VERSKEIE FUNKSIES DEUR VERSKILLENDE KATEGORIEË PERSONEEL (AANGEPAS UIT GRUNDY \& REINKE, 1973, p. 83)

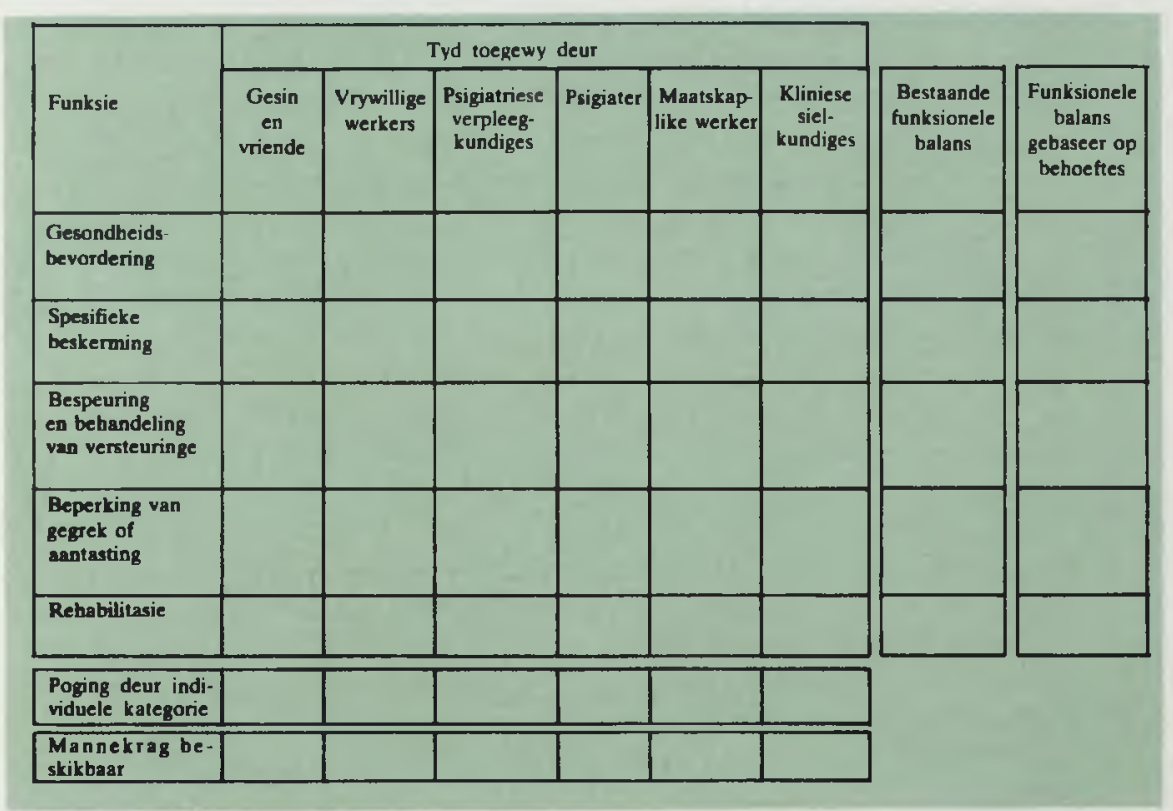

neer die standaarde van lewe en algemene opvoeding hoog is.

Behoefte en aanvraag is grotendeels afhanklik van 'n wye reeks sosiokulturele faktore. Nie een van die twee is op sigself ' $n$ toereikende basis vir besluitneming in die gesondheidsveld nie. Die verskil tussen hulle gee 'n aanduiding van die aanvaarbaarheid van die dienste in hulle huidige vorm. Dit is dus belangrik om die verskil tussen behoefte en aanvraag in gedagte te hou by die bepaling van behoeftes in die gemeenskap.

\section{BERAMING VAN DIE GEMEENSKAP}

\section{(Clark, 1978, p. 128-131)}

In die beraming van behoeftes in die gemeenskap is dit belangrik om die betrokke gemeenskap as 'n totaliteit te ontleed voor daar behoeftes bepaal kan word. 'n Mens moet jouself ook afvra: watter inligting is noodsaaklik vir die beraming van behoeftes in dié spesifieke gemeenskap? Vervolgens word kortliks riglyne aangestip oor
Verpleging, gesondheidsverbruikers.)

- Wat is die hulpbronne/middele/talente/bates wat die diens kan aanwend om sy doel te bereik? (Byvoorbeeld personeel, vrywilligers, fasiliteite, vir voorbeeld van ontleding wat gedoen kan word, sien tabel 3.)

- Uit watter afdelings bestaan die diens en wat is elke onderafdeling se doelstellings, aktiwiteite en maatstawe en evaluering? (Byvoorbeeld primêre, sekondêre en tersiêre voorkoming.)

- Hoe word die diens beheer? (beleid en prosedures, begroting, terugvoer en gevolgtrekkings).

- Filosofie.

$\mathrm{U}$ het al miskien reeds van hierdie inligting versamel. Aan die ander kant wil u moontlik met behulp van navorsingsmetodologie 'n opname in die gemeenskap maak om inligting te bekom en behoeftes te bepaal. U kan dus vraelyste uitstuur, gesels met verteenwoordigers van die gemeenskap of waarneem hoe die gemeenskap lyk en werk.

Hoe word behoeftes bevredig

- Hoe word afwyking en versteuring hanteer?

- Hoe word identiteite ontwikkel?

- Hoe word gemeenskapsfunksies uitgevoer?

Vir verdere uiteensetting van inligting wat nodig is om hierdie vrae te beantwoord, met spesifieke verwysing na geestesgesondheidsdienste, sien tabel 2. Die volgende vrae kan ook in hierdie beraming van die behoeftes in die gemeenskap gestel word as deel van 'n analise van die gemeenskap (Uys 1982, p. 19-32)

- Wat is die doelstellings van die gemeenskapsgesondheidsdienssentrum en in watter mate word hierdie doelstellings bereik?

- Wat is die omgewingsinvloede op hierdie diens, dit wil sê die gegewe wat ' $n$ invloed op die diens het maar waaroor die diens nie beheer het nie? (Byvoorbeeld die Departement van Gesondheid en Welsyn, Suid-Afrikaanse Raad op

\section{SAMEVATTING}

Uit die voorafgaande is dit duidelik dat die beraming van behoeftes in die gemeenskap deel uitmaak van 'n wetenskaplike proses: beraming, beplanning, implementering en evaluering van gemeenskapsdienste. Om die behoeftes in die gemeenskap so effektief as moontlik te beraam, is die gebruik van die beginsels van navorsingsmetodologie noodsaaklik. Deel van hierdie beginsels is om te weet wat jy gaan ondersoek en dus kriteria daar te stel vir die ondersoek. Daar is ook gepoog om aan te dui dat doeltreffende beraming van behoeftes in die gemeenskap bydra tot effektiewe gemeenskapsgesondheidsdienste. Aandag is ook gevestig op die verskil tussen behoefte en aanvraag in die gemeenskap. Laastens is daar 'n paar kriteria gestel waarvolgens 'n opname vir die beraming van behoeftes in die gemeenskap uitgevoer kan word. 


\section{BIBLIOGRAFIE}

Abdellah, Faye G. Benter patient care through nursing research Macmillan, New York. 1979

2. Abramson. J.H. Survey methods in community mediine Churchill Livingstone, Edinburgh. 1974.

3. Ackoff, R.L. Scientific merhod-optimizing applied research decisions. Wiley, New York. 1962

4. Bennett, A.E.; Ritchie, K. 1975. Questionaires in mediine: a guide to sheir design and use. Oxford University London, 1975.

5. Boldy, D. ed. Operational research applied to Health Services. Croom Helm. London, 1981

6. Brink, Pamela, J.; Wood, Marilynn. J. Basic steps in planning nursing research: from question to proposal North Scituate. MA: Duxburg. 1978.

7. Cilliers, S.P.. Maatskaplike navorsing: merodologie. prosedures, tegnieke. Kosmo, Stellenbosch, 1965.

8. Clark, Carolyn C., Mental health aspects of community health nursing. McGraw-Hill, New York, 1978.

9. Diers, Donna. Research in nursing practice, Lippencott. Philadelphia, 1979.

10. Fox, D.J., Fundamentals of research in nursing, Appleton-Century-Crofts, New York, 1976

11. Freedman, A.M.; Kaplan, H.I.; Sadock, B. Modern synopsis of the comprehensive texsbook of psychiatry II Williams \& Wilkins. Baltimore. 1977.

12. Haber. Judith; Leach, Anita, M.; Schudy, Sylvia, M Sidelean, Barbara, F. Comprehensive psychiatric nurs ing. McGraw-Hill. New York. 1978.

13. Grundy, F.: Reinke, W.A. Health practice research and formalized managerial methods. World Health Organization, Geneva 1973

14. Krampitz, S.D.; Pavlovich, Natalie, ed. Readings for nursing research C.V. Mosby, St. Louis, 1981.

15. Silverman, W.H. ed. Communiry mental health, a sourcebook for professionals and advisory board members. Praeger, New York. 1981

16. Uys, Leana, R. Gemeenskapspsigiatriese Verplees kunde. De Villiers, Bloemfontein. 1981

17. Uys. Leana. R. Kurrikulering in verpleegkunde. De Villiers. Bloemfontein, 1982

18. Wereley, Harrie1, H; Zuzich, Ann: Zajkowski. Myron; Zagornik. Dawn. A. Health research: the systems approach. Springer. New York, 1976

19. Williamson, Yvonne M. Research methodology and its implication in nursing. Wiley, New York, 1981.

20. Young. Pauline. V. Scientific social surveys and research: an introduction to the background, content, methods, principles and analysis of social studies. Prentice-Hall, Englewood Cliffs, 1956.
Tabel 2: RIGLYNE VIR DIE BERAMING VAN DIE GEMEENSKAP MET SPESIFIEKE VERWYSING NA GEESTESGESONDHEIDSDIENSTE

(Clark, 1978, p. 128-131)

1. WIE EN WAT IS DIE GEMEENSKAP? (Clark 1978 p. 128 \& 129) Van die vrae om te stel in die opname oor 'n gemeenskap is:

- Hoe word ruimte versprei en gebruik? (Waar is die hoëverdiepinggeboue, speelgronde en parke, begraafplase, verpleeginrigtings, oorbevolkte gebiede, natuurlike en fisiese blokkasies vir sosiale interaksie?).

- Wat is die kulturele vermenging en stabiliteit van die populasie? (Is daar een stel waardes en tradisies in die populasie of verskeie kulturele groepe wat in harmonie of konflik bly en hoeveel akkulturasie en spanning vind plaas as gevolg van mense wat in of uit die gebied trek?).

- Wat is die ouderdom, geslag en gesinsgroeperings? (Is hierdie hoofsaaklik 'n populasie van bejaardes, enkelbewonersgroep, jong huwelikspare met kinders, of 'n mengsel?).

- Watter vlakke van inkomste word verteenwoordig en in watter mate? (Is dit 'n relatiewe welgestelde bevolking wat private gesondheidsorg kan bekostig, 'n middelklasbevolking wat min hulp vir gesondheidsorg ontvang, 'n arm bevolking wat staats- of welsynshulp vir gesondheid ontvang, of is daar ' $n$ mengsel?).

- Wat is die vlakke van opvoeding? (Is die bevolking saamgestel uit sakemanne wat baie van hulself vereis en wat hul vrouens die gesin se gesondheidsaspekte laat hanteer? Is dit hoofsaaklik 'n optrede-georiënteerde bevolking wat leer deur te doen? Is daar 'n mengsel? Wat sê die beroepsvlak vir jou oor die bevolking se opvoeding, gesondheidsprobleme, probleemoplossingspatrone en metodes van leer?).

- Watter gemeenskapshulpbronne is beskikbaar en wie is hulle? (Waar is die skole, hospitale, inkopiesentra en klinieke geleë in verhouding tot beskikbare vervoer? Watter selfhelp- of ondersteuningsgroepe en dienste bestaan in die gemeenskap? Mense as hulpbronne?)

2. HOE WORD BEHOEFTES BEVREDIG? (Clark 1979, p. 129)

Daar kan aanvaar word dat alle mense basiese behoeftes het. Sommige van hierdie behoeftes word miskien nie bevredig nie of hulle bevrediging word voorkom deur ruimte, kultuur, ouderdom, geslag, gesin, inkomste, beroepsvlak of gemeenskapshulpbronfaktore.

Die geestesgesondheidsbehoeftes van 'n gemeenskap kan geidentifiseer word deur die gemeenskap se predikante, geneeshere, welsynsorganisasies en kliënte te vra watter behoeftes nie bevredig word nie.

\section{HOE WORD AFWYKING EN VERSTEURING HANTEER? (Clark.} 1978, p. 129 \& 130)

Hierdie area gaan oor 'n wye reeks hanteringsmeganismes van die gemeenskap van die sosiale isolasie van afwykendes na die instandhouding en ondersteuning van die persoon/persone in die gemeenskap wat afwykend is. Dit handel ook daaroor om uit te vind wat die omskrywing van afwyking in die gemeenskap is. Die volgende vrae in hierdie area kan in oorweging geneem word.

- Word mense met geestesgesondheidsprobleme verwerp deur die gemeenskap. Op watter wyse?

- Hoe word die homoseksuele, jeugmisdadigers, of daardie persone wat alkohol, dwelmmiddels of voedsel misbruik deur die gemeenskap behandel?

- Watter politieke, opvoedkundige of sosiale beskouings lei tot die verwerping van dié wat van die norm afwyk?

- Is daar menslike of hoogs geînstitusionaliseerde organisasies in die gemeenskap beskikbaar om met die hantering van afwykende lede te help? Wat is hulle?

- Verwerp die gemeenskap die gedagte dat fasiliteite vir afwykendes in die gemeenskap geplaas word? Hoe?

- Is daar 'n oorheersende beskouing dat mense wat afwyk van aanvaarde gedragspatrone gestraf behoort te word? Hoe word hierdie beskouing in die praktyk uitgevoer? 
4. HOE WORD IDENTITEITE ONTWIKKEL? (Clark, 1978, p. 130)

Vrae in hierdie area handel oor die identifisering van sosialiserende organisasies in die gemeenskap, en die bestudering van hoe hulle werk. Byvoorbeeld:

- Hoe leer gesinne hulle lede om op te tree?

- Watter soorte godsdienstige organisasies bestaan in die gemeenskap en wat is hulle oorheersende beskouing van menslike motivering?

- Watter jeugorganisasies is daar en hoe tree jong mense met hulle in verbinding?

- Watter soort formele en spesiale opvoedkundige programme is beskikbaar en hoe word hulle deur die gemeenskap gebruik?

- Hoe kan reeds bestaande organisasies effektiewer gebruik word?

5. HOE WORD GEMEENSKAPSFUNKSIES UITGEVOER? (Clark 1978 , p. $130 \& 131)$

Vir gemeenskapsfunksies om uitgevoer te word, moet daar kommunikasie, besluitneming, bande tussen verskeie subsisteme en wyses om die idee van gemeenskap te versterk, bestaan.

Die volgende is sommige vrae om by die beraming van dié gebied te vra.

- Word besluit gemaak voor voldoende inligting verkry word. Watter moontlike effek(te) kan dit hê?

- Word besluite toevallig gemaak, gebaseer op die persoonlike besorgdhede van 'n paar, of deur konsensus? Wat is die gevolge van hierdie soort besluitneming?

- Is kommunikasie gefragmenteer en ontoereikend? Hoe beĩnvloed sulke kommunikasie skynbaar die gemeenskap?

- Word gemeenskapsboodskappe gebaseer op 'n gemeenskapsgevoel (ons is almal saam hierin betrokke) of op stereotipes en die daarstelling van afstand tussen groepe (dit is ons teen hulle? Wat is die effek van beide soorte komunikasieboodskappe?

- Hoe akkuraat gee die plaaslike media inligting aan die gemeenskap weer?

- Is daar informele (gerugte) kommunikasiekanale?

- Word probleme informeel opgelos en komiteevergaderings slegs gebruik om vroeëre besluite neer te pen? Hoe kan dit die gemeenskap of besluitnemingsproses beînvloed?

- Hoe word ad hoc-, buurt, of blokassosiasies in besluitneming gebruik?

- Hoe geredelik word nuwelinge (insluitend verpleegkundiges) deur die gemeenskap aanvaar?

- Berus leierskap hoofsaaklik by 'n paar besigheids- en staatsgroepe of is dit wyd versprei in die gemeenskap?

- Is daar groot wisseling in mag of dikwelse veranderings in die magsbasis wat gesondheidsbeplanning of -behandeling kan beinvloed?

- Waar is mag gesetel, hoe word dit beskou en hoe word dit gebruik?

- Watter segmente van die gemeenskap is ontvanklik of vyandig vir buiteinvloede?

- Watter oorvleuelende areas en kettings wat kortkom bestaan daar in die geestesgesondheidsorgdiens?

- Is daar 'n gevoel van vertroue tussen gemeenskapslede en leiers?

- Is daar gemeenskapsdisintegrasie? (soos aangedui deur 'n onlangse ramp wat die basiese lewensmiddele van die gemeenskap aantas, wydverspreide ongesteldheid, uitermatige armoede, verwarring van kulturele waardes, verswakking van godsdienstige affiliasies, uitermatige migrasie van nuwe groepe, en vinnige sosiale verandering wat die tradisionele patrone van gemeenskapslewe affekteer).

\section{INLIGTING OOR \\ VERPLEEGNAVORSING BENODIG}

Die SA Verpleegstersvereniging wil weet van alle navorsing oor verpleging of die verpleegberoep wat voltooi of aan die gang is sodat dit gekoördineer en benut kan word. stel. Hiervoor word inligting benodig oor alle voltooide of lopende navorsing oor verpleging of die verpleegberoep. Dit sluit nie alleen navorsing vir studiedoeleindes in nie, maar ook klein of groot navorsingsprojekte en ondersoeke wat in die dienssituasie op plaaslike of departementele vlak gedoen is of word.

Die register wat op datum gehou gaan word, sal mettertyd aan enigeen wat daarvoor vra, beskikbaar gestel word. Dit sal ook gebruik word om leemtes te identifiseer en toekomstige navorsingsprioriteite te bepaal.

Persone wat inligting vir die register kan verskaf, moet asseblief met mev E Rademeyer by Posbus 1280, Pretoria, 0001 of tel. (012) 443306 in aanraking kom.

\section{INFORMATION ON NURSING RESEARCH REQUIRED}

To promote co-ordination and utilisation the SA Nursing Association would like to find out about all research on nursing or the nursing profession which is completed or is still being undertaken. Anyone who has undertaken relevant research or was involved in a project is asked to contact the Association.

One of the first tasks of the new nursing research unit at Head Office is to compile a national nursing research register. Information on all completed and current research on nursing or the nursing profession is required for this. Not only research undertaken for study purposes will be included, but also smaller or larger research projects and investigations undertaken in the service situation at local or departmental level.

The register, which will be updated regularly, will eventually be made available to all who are interested. It will also be used to identify shortcomings and to determine research priorities for the future.

Persons who can supply information for the register are asked to contact Mrs. E Rademeyer at P O Box 1280, Pretoria, 0001 or tel. (012) 443306.
Elkeen wat toepaslike navorsing gedoen het of by 'n projek betrokke was, word gevra om met die Vereniging in verbinding te tree.

Een van die eerste take van die nuwe navorsingseenheid by hoofkantoor is om 'n nasionale verpleegnavorsingsregister saam te 